\title{
Pendidikan Karakter melalui Kegiatan Ekstrakurikuler Tahfidz di SMA Negeri 5 Padang
}

\author{
Zulkifli Zulkifli ${ }^{1}$, Wirdanengsih Wirdanengsih ${ }^{2}$ \\ ${ }^{1,2}$ Universitas Negeri Padang \\ Email : zulkiflisosiologi01@gmail.com, wirdanengsih69@yahoo.com
}

\begin{abstract}
Abstrak
Penelitian ini bertujuan untuk mendeskripsikan pelaksanaan kegiatan Ekstrakurikuler Tahfidz di SMA Negeri 5 Padang, karakter apa saja yang dibentuk melalui kegiatan Ekstrakurikuler Tahfidz di SMA Negeri 5 Padang, serta mendeskripsikan faktor pendorong dan penghambat kegiatan pendidikan karakter melalui kegiatan Ekstrakurikuler Tahfidz di SMA Negeri 5 Padang. Metode penelitan yang digunakan dalam penelitian ini adalah metode penelitian kualitatif jenis deskriptif. Analisis data menggunakan teknik analisis interaktif dari Miles dan Huberman. Analisis interaktif Miles dan Huberman. Teori yang digunakan dalam penelitian ini adalah teori belajar sosial dari Albert Bandura. Untuk mendapatkan data peneliti melakukan observasi, wawancara dan studi dokumentasi. Hasil penelitian ini menunjukkan bahwa 1) Pelaksanaan kegiatan Ekstrakurikuler Tahfidz diadakan setiap hari senin, selasa, rabu, dan kamis pukul 06:00 WIB sampai pukul 07:00 WIB, 2) Karakter yang dibentuk pembinaan melalui kegiatan Ekstrakurikuler Tahfidz yaitu, karakter religius, karakter cinta membaca dan menghafal Al Qur'an, sopan santun, 3) Terdapat faktor pendorong dan fakor penghambat yaitu; faktor pendorong a) Mengembangkan bakat siswa sebab siswa yang sudah memiliki hafalan dan sudah lancar membaca Al Qur'an mereka diarahkan untuk mengikuti program Tahfidz. b) Ada kemudahan masuk perguruan tinggi kalau memiliki hafalan yang cukup banyak seperti 10 juz. c) Kearifan lokal Minangkabau, karena SMA Negeri 5 Padang terintegrasi kebudayaan Minangkabau sehingga sekolah membuat kegiatan Ekstrakurikuler Tahfidz sebab anak-anak minangkabau dulunya belajar mengaji di Surau. Sedangkan faktor penghambat adalah a) Pendanaan, b) Waktu pelaksanaan yang pendek, c) Siswa jenuh.
\end{abstract}

Kata kunci: Ekstrakurikuler Tahfidz, Karakter, SMA Negeri 5 Padang.

\section{Abstract}

This study aims to describe the implementation of extracurricular activities at SMAN 5 Tahfidz Padang, any character formed through Tahfidz Extracurricular activities at SMAN 5 Padang, and to describe the factors driving and inhibiting activities of character education through extracurricular activities Tahfidz in SMAN 5 Padang. Research method used in this research is a descriptive qualitative research methods. Analysis of data using interactive analysis techniques of Miles and Huberman. Miles and Huberman interactive analysis. The theory used in this study is the social learning theory of Albert Bandura. To get the data researchers conducted observations, interviews and documentation study. The results of this study indicate that 1) Implementation Tahfidz Extracurricular activities are held every Monday, Tuesday, Wednesday, and Thursday 06:00 am to 07:00 pm, 2) Characters are formed coaching through Tahfidz Extracurricular activities, namely, the religious character, character love to read and memorize the Qur'an, decorum, 3) are the drivers and inhibitors fakor namely; factors a) Develop talent of the students because students who already have already fluent memorization and recitation they are directed to follow Tahfidz program. b) There is a convenience to go to college if you have quite a lot like memorizing 10 chapters. c) Local knowledge Minangkabau, because SMAN 5 integrated Padang Minangkabau culture so that the school made Tahfidz Extracurricular activities because children once learned reading minangkabau Surau. While the inhibiting factors are a) Funding, b) short timeframe, c) Students saturated.

Keyword: Tahfidz Extracuriculer, Caracter, SMA Negeri 5 Padang

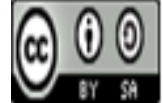

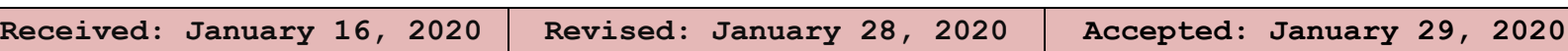




\section{Pendahuluan}

Pendidikan adalah usaha sadar yang dilakukan untuk meningkatkan pengetahuan dan membentuk kepribadian manusia. Menurut undang-undang nomor 20 tahun 2003 pasal 3 tentang sistem pendidikan nasional menyatakan bahwa pendidikan nasional berguna untuk mengembangkan kemampuan dan membentuk watak serta peradaban suatu bangsa yang bermartabat dalam rangka mencerdaskan kehidupan bangsa dan bertujuan mengembangkan potensi peserta didik menjadi manusia yang beriman dan bertakwa kepada tuhan Yang Maha Esa, berakhlak mulia, sehat, berilmu, cakap, krestif, mandiri dan menjadi warga negara yang demokratris serta bertanggung jawab(Kosim, 2012). Hornby dan Parnwell karakter merupakan kualitas mental atau moral, kekuatan moral, nama atau reputasi. Kertajaya juga menyatakan karakter merpakan "ciri khas" yang dimiliki oleh suatu benda atau individu. Ciri khas tersebut artinya "asli" dan mengakar pada kepribadian benda atau individu tersebut dan merupakan 'mesin' pendorong bagaimana seseorang bertindak, bersikap, berujar, dan merespon sesuatu (Ainissyifa, 2019).

Pelaksanaan pendidikan di Indonesia sekarang ini belum berjalan maksimal sesuai dengan hasil yang ingin dicapai. Hal ini bisa dilihat melalui proses pendidikan sekolah yang lebih mengutamakan penguasaan pengetahuan pada peserta didik dari proses pembelajaran (Fernandes, 2018). Kementrian pendidikan nasional 2010 menjelaskan tentang pendidikan karakter tidak hanya mengajarkan hal baik dan hal buruk saja, namun lebih luas dari hal tersebut. Pendidikan karakter yang baik tidak sekedar mengedepankan aspek pengetahuan tapi juga merasakan dengan baik atau loving good, moral feeling dan perilaku yang baik (moral action). Pendidikan karakter lebih menekankan terhadap habit atau kebiasaan yang terus menerus dikerjakan (Mega Mustika, 2019).

Sebuah hasil penelitian yang dilakukan oleh Hera terdapat kasus bullying di SMPN 7 Kinali. Adanya $83,33 \%$ siswa sering di bully oleh teman-temannya, 55,55\% siswa sering mem-bully, $66,67 \%$ siswa melakukan perilaku melabrak, kemudian ditemukan $44,44 \%$ siswa yang dilabrak, serta $44,44 \%$ siswa yang suka membully teman-temannya di media sosial (Hera Septiana Zega, 2019). Menurut Fatri Hanifah dalam Fenta (2018) pada sebuah survei di 33 provinsi yang dilakukan oleh Komnas Perlindungan Anak dan melakukan kerja sama dengan Lembaga Perlindungan Anak (LPA) pada Januari s/d Juni 2008. Kemudian hasil survei menunjukkan dari 4.500 remaja ditemukant 97\% Pelajar SMP dan SMA suka menonton film porno dan 93, 7\% Pelajar SMP dan SMA pernah berciuman (petting) dan oral seks (Hera Septiana Zega, 2019). Melihat kondisi tersebut menunjukkan degradasi moral melanda anak bangsa, maka perlunya pendidikan karakter untuk mengatasi permasalahan tersebut.

Bermunculannya fenomena yang terjadi di dalam kehidupan mengenai pendidikan dan dilakukan oleh pelajar menunjukkan bahwa pelaksanaan pendidikan di Indonesia belum mencapai hasil yang diharapkan seperti, tauran antar pelajar, bully, balapan liar, mengkonsumsi norkotika, cabut pada jam pembelajaran, dan pergaulan bebas bahkan ada yang melawan guru dan masih banyak lagi khasus yang lainnya.

Aspek pendidikan merupakan bagian terpenting dalam membentuk karakter bangsa. Mengukur kualitas pendidikan, bisa dilihat potret bangsa yang aslinya, sebab aspek pendidikan yang menentukan masa depan seseorang, mampukah menyumbangkan suatu yang membanggakan untuk bangsa dan bisat mengembalikan jati diri bangsa atau sebaliknya (Zulfitria, 2019).

Pendidikan karakter tidak hanya diterapkan dalam proses belajar dan mengajar dikelas saja, tetapi juga dapat diterapkan melalui kegiatan Ekstrakurikuler. Adanya kegiatan Ekstrakurikuler dapat mengembangkan keterampilan seseorang dan dapat mengembang kepribadian seseorang. Menurut Asmani mengemukakan bahwa kegiatan Ekstrakurikuler adalah kegiatan pendidikan diluar jam mata pelajaran dan pelayanan konseling untuk membantu pengembangan peserta didik sesuai dengan kebutuhan, potensi, bakat, dan, minat mereka melalui kegiatan khusus diselenggarakan oleh pendidik atau tenaga kependidikan yang berkemampuan dan berwenang disekolah (Lestari, 2016). Perlunya lingkungan yang baik bagi seseorang, karena lingkungan juga

Jurnal Sikola: Jurnal Kajian Pendidikan dan Pembelajaran Vol. 1, No. 3, Th. 2020 
merupakan salah satu agen dalam sosialisasi. Lingkungan yang baik akan memberikan dampak yang baik, sedangkan lingkungan yang buruk akan memberikan dampak yang buruk pula.

Menurut Yudi Prasetyo mendefinisikan kegiatan Ekstrakurikuler merupakan kegiatan yang dilakukan diluar mata pelajaran untuk membantu mengembangkan kemampuan peserta didik, seperti minat dan bakat melalui kegiatan yang diselenggarakan oleh pendidik atau tenaga kependidikan yang memiliki kemampuan dan wewenang disekolah/madrasah. Sedangkan Oemar Hamalik mengemukakan bahwa kegiatan Ekstrakurikuler adalah suatu kegiatan pendidikan yang tidak termasuk dalam ketentuan kurikulum yang berlaku, tetapi bersifat paedagogis dan menunjang untuk tercapainya tujuan sekolah (Efendi, 2019). hampir semua orang tua memilih sekolah berdasarkan Ekstrakurikuler yang dimiliki sekolah agar dapat mengembangkan bakat dan minat yang dimiliki anak. (Yunanda, Fernandes, Sylvia, \& Putra, 2019).

SMA Negeri 5 Padang memiliki 22 kegiatan Ekstrakurikuler, diantaranya adalah Rohis, Tahfidz, Bina remaja islam, PIK R, Paski, Pramuka PA, Pramuka PI, Pramuka Ekskul, OSN, Seni, Olahraga, Sekolah BAM, Sekolah Adiwiyata, Mulok dan Keterampilan, Kewirausahaan, Robotik, PMR, Literasi, KTI, Bahasa Inggris, Bahasa Arab, dan Bahasa Jepang.

Tahfidz merupakan salah satu kegiatan ekstrakuriker yang ada di SMA Negeri 5 Padang. Tahfidz adalah bagian pendidikan karakter dalam bidang keagamaan. Tujuannya yaitu mendekatkan manusia dengan Al Qur'an. Al Qur'an tidak sekedar kitab biasa tetapi al-Qur'an adalah sumber utama dan pertama ajaran Islam serta menjadi pedoman kehidupan manusia yang Allah turunkan kepada Nabi Muhammad SAW, selain itu merupakan rahmat yang tak ada tara bagi alam semesta (Devi Ayu Prawindar Wulan dan Ismanto, 2012). Prinsip dasar dalam pendidikan siswa salah satunya ialah dengan ikatan rohani dengan cara mengikat anak dengan al quran. Ikatan dengan al quran memberikan kejernihan, keikhlasan dalam diri, kesucian jiwa (Nadhiroh, 2019). Ekstrakurikuler Tahfidz mampu mengembangkan pengetahuan siswa, menaikkan tingkat keimanan dan ketakwaan siswa kepada Allah SWT melalui nilai religius dengan pelaksanaan program keagamaan tersebut (Surur, 2018)

Munculnya Tahfidz di SMA Negeri 5 Padang karena masih banyak siswa yang belum bisa atau belum lancar membaca Al Quran. Hal ini ditunjukkan saat penerimaan peserta didik baru, bagi yang mendaftar di sekolah ini mereka di tes membaca Al Quran, disanalah bisa diketahui siswa yang tidak bisa membaca Al Quran, belum lancar dan lancar. Bagi yang sudah memiliki dasar atau memiliki hafalan akan diarahkan mengikuti Tahfidz dan yang belum lancar membaca Al Quran akan diarahkan mengikuti tahsin. Penelitian ini bertujuan untuk mengatahui pendidikan karakter melalui kegiatan Ekstrakurikuler di SMA Negeri 5 Padang.

Penelitian sebelumnya yang berhubungan dengan pendidikan karakter pertama penelitian yang dilakukan oleh Musyanto tentang "Pendidikan Karakter dalam Pembelajaran Tahfidz Al Qur'an SDIT Iqra 1 Kota Bengkulu" dengan temuan 1) karakter religius diterapkan melalui berwudhu sebelum belajar Tahfidz, berdoa sebelum dan sesudah belajar Tahfidz, puasa senin kamis dan shalat 5 waktu, dan qiyamulail. 2) karakter bersih diterapkan melalui berwudhu sebelum belajar, pakaian yang bersih, tempat belajar yang bersih dan mengunakan alat-alat yang bersih. 3) karakter disiplin dilihad dari datang tepat waktu, disiplin mengulang hafalan, dan menyetor hafalan. 4) karakter istiqamah diterapkan dengan keistiqomahan dalam mengulang, menghafal dan menyetor hafalan. 5) karakter sabar diterapkan melalui kesabaran dalam mengulang hafalan, sabar dalam menyetor hafalan (Musyanto, 2016).

Kedua, penelitian yang dilakukan oleh Duma Mayasari dengan temuan pembelajaran tahsin dan Tahfidz Al Qur'an di Madrasah Aliyah Islamic Centre Sumatera Utara dapat membentuk karakter peserta didik memiliki akhlak atau moral, dalam diri peserta didik tertanam rasa keikhlasan, disiplin, kejujuran, kesabaran, amanah, religius, kerja keras, istiqamah dan bertanggungjawab, kemudian diterapkan dalam kehidupan sehari-hari baik dalam lingkungan sekolah maupun masyarakat (Mayasari, 2013). Berdasarkan pendapat diatas salah satu faktor yang mempengaruhi hasil belajar peserta didik adalah faktor internal yaitu karakter peserta didik. (Nadya Zahratul Atika, 2019)

Jurnal Sikola: Jurnal Kajian Pendidikan dan Pembelajaran Vol. 1, No. 3, Th. 2020 
Berdasarkan latar belakang diatas, maka penelitian ini diberi judul pendidikan Karakter Melalui Kegiatan Ekstrakurikuler di SMA Negeri 5 Padang. Penelitian ini bertujuan untuk 1) mengetahui pelaksanaan kegiatan Tahfidz di SMA Negeri 5 Padang. 2) mengetahui karakter seperti apa yang dibentuk melalui kegiatan Tahfidz. 3) mengetahui faktor pendorong dan penghambat kegiatan Tahfidz di SMA Negeri 5 Padang. Penelitian ini menggunakan Teori Belajar Sosial dari Albert Bandura.

\section{Metode Penelitian}

Peneliti melakukan penelitian di SMA Negeri 5 Padang jl. Raya Balai Baru, Kuranji, Kota Padang, Sumatera Barat. Metode yang dipakai adalah metode kualitatif jenis deskriptif. Penelitian kualitatif menurut Denzin dan licoln adalah multi metode dalam fokus, termasuk pendekatan interpretif dan naturalistik terhadap suatu pokok persoalannya. Sedangkan menurut boglan dan Taylor mengemukakan metode kualitatif adalah sebuah prosedur penelitian yang nantinya menghasilkan data deskriptif: ucapan atau tulisan dan perilaku yang dapat diamati dari orangorang (subjek) itu sendiri (Rulam, 2014). Pemilihan informan penelitian menggunakan teknik purposive sampling yang mana peneliti memilih informan yang dianggab mengetahui keadaan sosial dan bisa memberikan informasi atau data yang diinginkan yaitu Kepala sekolah, Wakil Kesiswaan, Koordinator kegiatan Tahfidz, Ustadz dan Ustadzah yang mengajar Tahfidz.

Kemudian, untuk mengumpulkan data hal pertama yang peneliti lakukan adalah observasi. Langkah ini peneliti lakukan untuk mendapatkan data terkait pelaksaan kegiatan Tahfidz di SMA Negeri 5 Padang. Selanjutnya, peneliti melakukan wawancara untuk mendapatkan data yang lebih mendalam lagi. Lalu, cara yang dilakukan adalah studi dokumentasi gunanya menambah kekuatan data yang peneliti dapatkan.

\section{Hasil dan Pembahasan}

Berdasarkan hasil penelitian bahwa pelaksananan kegiatan Ekstrakurikuler Tahfidz di SMA Negeri 5 Padang sebagai berikut ;

\section{Latar Belakang Kegiatan Tahfidz}

Kemerosotan akhlak generasi muda dan jauhnya dari nilai-nilai religius membuat pihak sekolah untuk mengatasi fenomena tersebut dengan cara melahirkan suatu kegiatan Ekstrakurikuler Tahfidz sebagai sarana untuk membina siswa melalui pendekatan dengan Al Qur'an. Upaya ini tidak terlepas dari Visi dan Misi SMA Negeri 5 Padang. Visi SMA Negeri 5 Padang adalah "Bertaqwa, berprestasi, terampil, kompetitif, dan cinta lingkungan". Sedangkan Misinya, 1) Melaksanakan pembacaan Al-Qur'an, Asmaul Husna, berdoa setiap pagidan sholat Zuhur berjamaah, sholat Dhuha serta kultup setiap Jumat pagi. 2) Meningkatkan karakter peserta didik melalui Pendidikan Al-Qur'an dan Budaya Alam Minangkabau. 3) Menggunakan kalimat motivasi "JUARA" (Jujur Ulet Aktif Raih Asa) disetiap kegiatan yang dilakukan. 4) Meningkatkan prestasi akademik peserta didik melalui Olimpiade Sains Nasional (OSN) inimal tingkat kota Padang Tahun Ajaran 2019/2020. 5) Meningkatkan prestasi non akademik (ekstrakulikuler) peserta didik sampai tingkat nasional Padang tahun pelajaran 2019/2020. 6) Meningkatkan keterampilan peserta didik dalam pertandingan olahraga tingkat kota padang, tingkat provinsi dan tingkat nasional pada tahun pelajaran 2019/2020. 7) Meningkatkan kompetensi lulusan yang diterima di Perguruan Tinggi Negeri tahun pelajaran 2019/2020. 8) Menjadi Juara Sekolah Adiwiyata tingkat Nasional tahun pelejaran 2019/2020. 9) Melaksanakan gerakan spontanitas terhadap kebersihan lingkungan sekolah dengan ikon "ABSTRAKS" (Ambil Sampah, Tempatkan, Rapikan di Bak Sampah). 10) Mewujudkan tenaga pendidikan, tenaga kependidikan dan peserta didik yang berwawasan lingkungan. 11) Menciptakan dan membudayakan lingkungan yang bersih, sehat, nyaman, asri, aman dan damai. 


\section{Peserta Tahfidz}

SMA Negeri 5 Padang ketika Penerimaan Peserta Didik Baru (PPDB) melakukan tes baca Al Qur'an dan mendata siswa yang memiliki hafalan. Disanalah bisa diketahui mana siswa yang bisa membaca Al Qur'an dan mana yang tidak, lalu mengetahui siswa yang memiliki hafalan. Setelah mengetahui hal tersebut siswa diarahkan untuk mengikuti kegiatan Ekstrakurikuler Tahfidz bagi yang sudah mempunyai hafalan atau yang sudah lancar membaca Al Qur'an dan bagi bagi siswa yang belum lancar membaca Al Quran mereka diarahkan untuk mengikuti program tahsin.

\section{Ustadz dan Ustadz}

Ustadz dan Ustazah merupakan sebutan untuk orang yang mengajar kegiatan Tahfidz. Guru Tahfidz bukanlah guru yang mengajar di SMA Negeri 5 Padang melainkan orang dari kerjasama dengan Yayasan Ar Risalah dan Lembag Tahfidz Masjid Nurul Iman Padang.

\section{Waktu dan Tempat Pelaksanaan}

Kegiatan Tahfidz dilaksanakan di selama empat hari dari Senin, Selasa, Rabu, dan Kamis pukul 06:00 WIB sampai pukul 07:00 WIB di Mushala SMA Negeri 5 Padang. Alasan dilaksanakan pukul 06:00 WIB, karena pada jam ini kerja otak lebih baik sehingga lebih mudah menghafal Al Quran dan mengulang hafalan.

\section{Bentuk-bentuk Kegiatan Tahfidz}

Berdasarkan hasil penelitian bentuk-bentuk kegiatan Ekstrakurikuler Tahfidz di SMA 5 Negeri Padang

\section{Menghafal dan Muraja'ah hafalan}

Kegiatan menghafal dan muraja'ah hafalan dilakukan sebelum menyetor hafalan kepada ustadz atau ustadzah. Siswa yang baru datang mereka langsung mengambil posisi untuk menghafal dan muraja'ah hafalan sebelum disetor dan sambil menunggu kedatangan ustazd atau ustadzah.

\section{Setor Hafalan}

Kegiatan setor hafalan dilakukan ketika ustazd atau ustadz sudah datang dan setelah siswa menghafal dan muraja'ah hafalan lalu yakin dengan hafalan tersebut barulah di setor. Hafalan yang akan disetorkan minimal tiga ayat, setelah setor hafalan.

\section{Motivasi}

Motivasi merupakan kata-kata yang disampaikan oleh ustadz atau ustdzah setelah siswa melalukan setor hafalan mereka. Gunanya motivasi untuk penyamangat supaya siswa tidak jenuh dan lebih semangat lagi menghafal Al Quran.

\section{Tahsin}

Tahsin merupakan kegiatan belajar membaca Al Quran. Tahsin ini dikhususkan bagi siswa yang belum bisa atau belum lancar membaca Al Qur'an. Sebelum mengikuti Tahfidz siswa diarahkan dulu untuk mengikuti tahsin sampai lancar dan benar dalam membaca Al Quran.

\section{Karakter yang dibentuk melalui kegiatan Ekstrakurikuler Tahfidz}

Adapun karakter yang dibentuk melalui kegiatan Ekstrakurikuler Tahfidz di SMA Negeri 5 Padang adalah:

\section{Karakter Religius}

Karakter religius sangat dibutuhkan oleh para peserta didik untuk menghadapi degradasi moral, agar mereka mampu memiliki dan berperilaku dengan ukuran baik dan buruk yang didasarkan pada ketentuan dan ketetapan agama (Safitri \& Novirizka Hasan, 2018). SMA Negeri 5 Padang merupakan salah satu sekolah yang memiliki program pendidikan karakter. Tahfidz merupakan salah satu program yang digagas untuk membentuk karakter siswa yang religius.

Jurnal Sikola: Jurnal Kajian Pendidikan dan Pembelajaran Vol. 1, No. 3, Th. 2020 
Dengan menggunakan pendekatan nilai-nilai keagamaan akan mengontrol siswa dalam melakukan yang buruk. Terjadinya kemunduran moral generasi muda juga disebabkan jauhnya dari nilai-nilai agama. Melalui Tahfidz dapat membentengi siswa melakukan keburukan. Sebelum memulai aktivitas siswa disuruh berwudhu, kemudian melakukan shalat sunnah dua rakaat.

\section{Karakter Cinta Membaca dan Menghafal Al Qur'an}

Setiap muslim mempunyai kewajiban untuk mengenali Alquran, mempelajari, mengimplementasikan isinya serta mengsyi'arkannya atau mengajarkan ke orang lain (Wirdanengsih, 2016). Era modernisasi saat ini membuat generasi muda jauh dari nilai-nilai agama. Generasi muda saat ini disibukkan oleh dunia masing-masing seperti balapan liar, pergaulan bebas, game online, sehingga waktu mereka habis dengan sia-sia. Melihat kondisi seperti itu dan banyaknya peserta didik yang tidak bisa membaca Al-Quran maka, SMA Negeri 5 Padang membuat program Tahfidz untuk mengatasi hal tersebut dan mewujudkan visi serta misi sekolah.

\section{Karakter Sopan Santun}

Sopan santun juga dapat diartikan sebagai suatu tingkah laku seseorang dalam kehidupan sehari-hari harus sesuai dengan kodratnya, tempat, waktu dan kondisi lingkungannya dimana siswa itu berada, sehingga membuat siswa itu akan sukses dalam pergaulannya atau dalam hubungan sosialnya dan akan sukses dalam kehidupan keseluruhannya (Roshita, 2015). Ketika sampai ke mushala siswa langsung bersalaman dengan ustadz dan ustadzah. Saat menyetor hafalan mereka tidak mendahului temannya meskipun berbeda tingkatan antara kelas X dengan kelas XI.

Faktor pendorong dan penghambat kegiatan Ekstrakurikuler Tahfidz di SMA Negeri 5 Padang

Berdasarkan hasil penelitian bahwa terdapat beberapa faktor pendorong dan penghambat kegiatan Ekstrakurikuler di SMA Negeri 5 Padang.

\section{Faktor pendorong}

Faktor pendorong kegiatan Ekstrakurikuler Tahfidz di SMA Negeri 5 Padang yaitu;

\section{Mengembangkan bakat siswa}

Sebagian siswa sudah memiliki kemampuan dasar atau sebelum masuk ke SMA Negeri 5 Padang sebagian sudah ada yang memiliki hafalan. Maka, bagi siswa yang sudah memiliki potensi mereka disrahkan untuk mengikuti Tahfidz.

\section{Siswa yang hafal Al Qur'an dimudahkan masuk perguruan tinggi}

Salah satu faktor pendorong adanya kegiatan Ekstrakurikuler Tahfidz adalah bagi siswa yang memiliki hafalan mereka akan diberi kemudahan untuk masuk perguruan tinggi, karena ada sebagian perguruan tinggi yang memberi kemudahan bagi yang hafal Al Quran.

\section{Kearifan Lokal Minangkabau}

Sebagai sekolah yang terintegrasi kebudayaan minangkabau sehingga SMA Negeri 5 Padang membuat program Tahfidz mengingat masyarakat minangkabau dulunya terkenal dengan pendidikan Surau, dimana Surau ini digunakan sebagai tempat belajar termasuk belajar mengaji. Supaya kearifan lokal minangkabau tidak hilang meskipun sudah memasuki zaman modern. Selain itu masyarakat minangkabau juga memiliki falsafah adat yaitu Adat Basandi Syarak, Syarak Basandi Kitabullah (ABS-SBK) menjadi faktor pendorong pihak sekolah untuk mengadakan program Tahfidz.

\section{Generasi muda yang jauh dari Al Qur'an}

Melihat fenomena yang terjadi saat ini seperti, tauran, pegaulan bebas, LGBT dan sebagainya disebabkan beberapa faktor salah satunya jauhnya dari Al Quran. Orang yang dekat dengan agama atau Al Quran akan terjaga dari perbuatan buruk. 


\section{Faktor penghambat}

Adapun faktor penghambat kegiatan Ekstrakurikuler Tahfidz di SMA Negeri 5 Padang.

\section{Pendanaan}

Pelaksanaan Tahfidz juga memiliki hambatan dalam pendanaan. Pendanaan kegiatan Tahfidz tidak didanai oleh dana BOS, karena Tahfidz termasuk program diluar program formal sekolah. Mengatasi hal tersebut melakukan rapat dengan wali murid khusus anaknya yang ikut program Tahfidz untuk membahas biaya operasional program Tahfidz.

\section{Waktu yang pendek}

Pelaksanaan Tahfidz pukul 06:00 WIB sampai 07:00 WIB ternyata waktu tersebut terasa singkat dan membuat siswa tidak maksimal dalam mengahafal atau muraja'ah hafalan. Disisi lain ada juga siswa yang datang terlambat karena waktunya yang terlalu bagi dan jarak tempat tinggal yang cukup jauh.

\section{Siswa yang jenuh}

Al Quran membutuhkan komitmen yang tinggi. Selama perjalanan Tahfidz ada siswa yang semangat dan ada juga yang merasa jenuh karena merasakan sulitnya menghafal Al Quran. Selama perjalanan Tahfidz ada siswa yang semangat dan ada juga yang merasa jenuh karena merasakan sulitnya menghafal Al Quran. Kemudian siswa diberikan motivasi setelah mereka setor hafalan masing-masing.

Berdasarkan hasil penelitian bahwa pendidikan karakter di SMA Negeri 5 Padang dilakukan salah satunya dengan kegiatan Ekstrakurikuler Tahfidz. Program Tahfidz merupakan salah satu upaya untuk memujudkan visi dan misi SMA Negeri 5 Padang. Melalui pendekatan dengan Al Qur'an dapat membentengi peserta didik untuk melakukan tindakan buruk yang dilarang dalam Al Qur'an. Pendidikan karakter melalui program Tahfidz melalaui motivasi yang diberikan oleh ustadz atau ustadzah dengan tujuan peserta didik tidak hanya menghafal atau belajar membaca Al Qur'an saja, tetapi juga mengamalkan isi yang terkandung didalamnya. Melaksanakan shala sunnah dua rakaat ketika masuk mushala merupakan upaya membetuk karakter peserta didik dan menjaga tingkat keimanan mereka karena shalat mencegah dari hal yang buruk. Melalui lingkungan yang kondusif atau lingkungan yang baik mampu mengontrol peserta didik untuk melakukan suatu tindakan.

Penelitian ini mengunakan teori belajar sosial yang dikemukakan oleh Albert Bandura. seseorang dapat mengambil pembelajaran dengan peniruan (imitation) apa yang terjadi dilingkungan sekitarnya berupa tindakan yang dilakukan orang lain. Selanjutnya, pembiasaan merespon (conditioning) merupakan seseorang dapat mempelajari mana tindakan yang baik dan mana yang buruk melalui perilaku yang menghasilkan ganjaran dan perilaku yang menimbulkan sanksi (Syah, 2009). Lingkungan yang diciptakan dalam kegiatan Tahfidz membuat peserta didik meniru tindakan yang ada sekitarnya. Melalui kegiatan Tahfidz siswa dapat menilai mana tindakan yang baik dan mana tindakan yang buruk sehingga siswa berfikir untuk melakukan suatu tindakan mengenai tindakan mana yang mendapatkan ganjaran dan tindakan yang mendapatkan hukuman. Siswa yang mengikuti program Tahfidz akan lebih dutamakan mengikuti perlombaan seperti MTQ sebagai reward.

\section{Kesimpulan}

Pelaksanaan kegiatan Ekstrakurikuler di SMA Negeri 5 Padang dilaksanakan selama empat hari setiap minggunya yaitu hari senin sampai kamis. Adapun kegiatannya adalah mengafal Al Quran, murajaah hafalan, setor hafalan kepada ustdz atau ustadzah, motivasi yang diberikan oleh ustadz atau ustadzah, kemudian ada tahsin atau belajar membaca Al Quran. Berdasarkan teori belajar sosial dari Albert Bandura bahwa siswa akan melakukan peniruan (imitation) perilaku atau tindakan yang ada disekitarnya. 
Tidakan yang dilakukan secara berulang-ulang, seperti melakukan shalat sunnah at tahiyatul masjid, kemudin bersalaman dengan Ustadz Ustadzah dan teman-teman disekitarnya yang mana hal ini dilakukan secara berulang-ulang kemudian siswa menginternalisasikan kedalam dirinya sebagai bentuk kebiasaan merespon (conditioning) dan siswa mengetahui mana tindakan baik dan tindakan buruk sebelum menginternalisasikan kedalam dirinya sehingga terbentuklah karakter pertama, karakter religius, SMA Negeri 5 Padang merupakan sekolah yang tidak hanya menuntut aspek kognitif saja, tetapi juga menuntut aspek religius. Hal tersebut diwujudkan melalui program membentuk karakter religius seperti shalat zuhur berjamaah di lapangan sekolah dan dimushala sekolah, 15 menit sebelum guru mengajar siswa diminta untuk membaca Al Quran, membaca asmaul husna, kultum jumat. Kedua, karakter disiplin dapat dilihat ketika siswa yang mengikuti Tahfidz dari pada siswa yang lain, kalau ada siswa yang ikut Tahfidz terlambat mereka tidak boleh lagi mengikuti Tahfidz pada hari itu. Ketiga, karakter sopan santun bias dilihat saat siswa bersalaman ketika sebelum dan sesudah melakukan setor hafalan.

\section{Daftar Pustaka}

Ainissyifa, H. (2019). Pendidikan Karakter dalam Perspektif Pendidikan Islam. Mumtaz: Jurnal Studi Al-Qur'an Dan Keislaman, 2(1), 1-26. https://doi.org/10.36671/mumtaz.v2i1.17

Devi Ayu Prawindar Wulan dan Ismanto. (2012). Pembelajaran ekstrakurikuler tahfidz al- qur'an di madrasah aliyah. The 1st Education and Language International Conference Proceedings Center for International Language Development of Unissula, 236-246.

Efendi, M. S. (2019). Pendidikan Karakter Siswa Melalui Kegiatan Ekstrakurikuler Keagamaan Kerohanian Islam (Rohis) di SMPN 1 Probolinggo. Etheses, 53(9), 1689-1699. https://doi.org/10.1017/CBO9781107415324.004

Fernandes, R. (2018). Adaptasi Sekolah Terhadap Kebijakan Pendidikan Inklusif. Socius, 4(2), 120. https://doi.org/10.24036/scs.v4i2.16

Hera Septiana Zega, I. S. (2019). Perilaku Bullying Pada Siswa SMPN 7 Kinali Kabupaten $\begin{array}{llll}\text { Pasaman Barat. Jurnal 200-207. } & \end{array}$ https://doi.org/http://dx.doi.org/10.24036/perspektif.v2i3.90

Kosim, M. (2012). Urgensi Pendidikan Karakter. Karsa: Journal of Social and Islamic Culture, 19(1), 84-92. https://doi.org/10.19105/karsa.v19i1.78

Lestari, R. Y. (2016). Peran Kegiatan Ekstrakurikuler Dalam Mengembangkan Watak Kewarganegaraan Peserta Didik. Untirta Civic Education Journal, 1(2), 136-152. https://doi.org/10.30870/ucej.v1i2.1887

Mayasari, D. (2013). Internalisasi Nilai-nilai Karakter Peserta Didik dalam Pembelajaran Tahsin dan Tahfidz Al Qur'an Yayasan Islamic Center Sumatera Utara. Repository, 53(9), 16891699. https://doi.org/10.1017/CBO9781107415324.004

Mega Mustika, W. (2019). Pendidikan Karakter melalui Mentoring (Studi Kasus: Siswa Perempuan SMP Perguruan Islam Ar-Risalah Kota Padang). Jurnal Sikola: Jurnal Kajian Pendidikan Dan Pembelajaran, 53(9), 1689-1699. https://doi.org/10.1017/CBO9781107415324.004

Musyanto. (2016). Pendidikan Karakter dalam Pembelajaran Tahfizd Al Qur'an di SDIT Iqra 1 Kota Bengkulu. Al-Bahtsu: Jurnal Penelitian Pendidikan Islam, 1(14). https://doi.org/http://dx.doi.org/10.29300/btu.v1i1.398

Nadhiroh, L. (2019). Implementasi Pendidikan Karakter Melalui Program Tahfidz Al Quran Siswa Kelas IV MIN Kalibuntu Wetan Kendal Tahun Ajaran 2017/2018. Proceedings of the National Education Seminar, 4(1), 75-84. https://doi.org/.1037//0033-2909.I26.1.78

Nadya Zahratul Atika, J. J. (2019). Hubungan Karakter Siswa dengan Hasil Belajar Sosiologi Siswa Kelas X dan XI IPS di SMA Negeri 2 Batang Anai Kabupaten Padang Pariaman. Sikola, 1(1), 20-27. https://doi.org/https://doi.org/10.24036/sikola.v1i1.4 
Roshita, I. (2015). Upaya Meningkatkan Perilaku Sopan Santun Melalui Layanan Bimbingan Kelompok Dengan Teknik Sosiodrama. Jurnal Penelitian Tindakan Bimbingan \& Konseling, 1(2), 29-35.

Rulam, A. (2014). Metode Penelitian Kualitatif. Yogyakarta: AR-Ruzz Media.

Safitri, N. E., \& Novirizka Hasan, S. U. (2018). Strategi Layanan Bimbingan Dan Konseling Dalam Pengembangan Nilai Karakter Religius. Jurkam: Jurnal Konseling Andi Matappa, 2(1), 19. https://doi.org/10.31100/jurkam.v2i1.64

Surur, A. M. (2018). Upaya Menanamkan Nilai Religius Siswa Di Man Kediri 1 Kota Kediri Dengan Ekstrakurikuler Keagaman Tahfidz Al-Qur'an. Jurnal Pendidikan Agama Islam, 15(1), 42-51. https://doi.org/10.14421/jpai.2018.151-03

Syah, M. (2009). Psikologi Belajar. Depok: Rajawali Pers.

Wirdanengsih. (2016). Pembudayaan Tradisi Membaca Alquran pada anak-anak di Masyarakat Balai Gurah Kabupaten Agam Sumatera Barat. Akademika: Jurnal Keagamaan Dan Pendidikan, 12, 27-33.

Yunanda, D., Fernandes, R., Sylvia, I., \& Putra, E. V. (2019). Pilihan Rasional Orang Tua Menyekolahkan Anak ke SDIT Adzkia Padang. 1(2), 127-138. https://doi.org/https://doi.org/10.24036/sikola.v1i2.17

Zulfitria. (2019). Pembelajaran Tahfidz al-Qur'an Dalam Pendidikan Karakter Anak Usia Dini. Darul Ilmi: Jurnal Ilmiah Pendidikan Islam Anak Usia Dini, 53(9), 1689-1699. https://doi.org/10.1017/CBO9781107415324.004 